\title{
HLA-Bw4 Antigen
}

National Cancer Institute

\section{Source}

National Cancer Institute. HLA-Bw4 Antigen. NCI Thesaurus. Code C71269.

HLA-BW4 antigen is the public epitope associated with the sequence of amino acid residues at positions 77-83 in the alpha one domain of the HLA class I heavy chain. These epitopes exist on proteins encoded by certain alleles of both the human HLA-B gene and the human HLA-A gene. 